\title{
Effects of a 6-month exercise program pilot study on walking economy, peak physiological characteristics, and walking performance in patients with peripheral arterial disease
}

\author{
This article was published in the following Dove Press journal: \\ Vascular Health and Risk Management \\ 12 April 2012 \\ Number of times this article has been viewed
}

\author{
Robert G Crowther' \\ Anthony S Leicht' \\ Warwick L Spinks' \\ Kunwarjit Sangla ${ }^{2}$ \\ Frank Quigley ${ }^{2}$ \\ Jonathan Golledge $e^{2,3}$ \\ 'Institute of Sport and Exercise \\ Science, James Cook University, \\ Townsville, Queensland, Australia; \\ ${ }^{2}$ Townsville Hospital, Townsville, \\ Queensland, Australia; ${ }^{3}$ The Vascular \\ Biology Unit, James Cook University, \\ Townsville, Queensland, Australia
}

Correspondence: Robert Crowther Institute of Sport and Exercise Science Rehabiliation and Exercise Science Building, James Cook University Townsville Queensland 48II, Australia

Tel +6I 7478 I 6550

Fax +6I $7478 \mid 6688$

Email robert.crowther@jcu.edu.au

\begin{abstract}
The purpose of this study was to examine the effects of a 6-month exercise program on submaximal walking economy in individuals with peripheral arterial disease and intermittent claudication (PAD-IC). Participants $(n=16)$ were randomly allocated to either a control PAD-IC group (CPAD-IC, $\mathrm{n}=6$ ) which received standard medical therapy, or a treatment PAD-IC group (TPAD-IC; $\mathrm{n}=10$ ) which took part in a supervised exercise program. During a graded treadmill test, physiological responses, including oxygen consumption, were assessed to calculate walking economy during submaximal and maximal walking performance. Differences between groups at baseline and post-intervention were analyzed via Kruskal-Wallis tests. At baseline, CPAD-IC and TPAD-IC groups demonstrated similar walking performance and physiological responses. Postintervention, TPAD-IC patients demonstrated significantly lower oxygen consumption during the graded exercise test, and greater maximal walking performance compared to CPAD-IC. These preliminary results indicate that 6 months of regular exercise improves both submaximal walking economy and maximal walking performance, without significant changes in maximal walking economy. Enhanced walking economy may contribute to physiological efficiency, which in turn may improve walking performance as demonstrated by PAD-IC patients following regular exercise programs.
\end{abstract}

Keywords: vascular disease, peripheral vascular disease, walking economy

\section{Introduction}

Peripheral arterial disease (PAD) is a common circulatory problem arising from decreased blood flow, and is usually secondary to atherosclerosis in the arteries of the lower limbs. The most common presenting symptom of PAD is intermittent claudication (IC), with exercise-induced pain experienced in the calves, thighs or buttocks that is relieved with rest. ${ }^{1,2}$ Compared to healthy, age-matched controls, patients with PAD-IC demonstrate reduced physiological capacity, limited lower limb mobility (temporal-spatial parameters and joint angular kinematics), poor walking performance (maximal walking distance/time), low physical activity levels, and decreased health-related quality of life..$^{3-7}$

Over the past 4 decades, numerous studies have employed short- and long-term treadmill walking programs for PAD sufferers, resulting in significant improvement in both pain-free walking and maximal walking times. ${ }^{7-9}$ However, the mechanism(s) for such enhanced walking performance has yet to be determined. A variety of possible mechanisms have been suggested, including increased blood flow, improved mitochondrial oxidative 
capacity, greater skeletal muscle diffusive capacity, capillary growth, higher oxygen perfusion in the area of the arterial obstruction, advances in walking economy (ie, a decrease in whole-body oxygen uptake), and changes in lower limb gait characteristics. ${ }^{6,10-15}$ Determination of the mechanisms for improved walking performance will provide clinicians with valuable information for the prescription and management of treatment plans for PAD-IC patients.

In our previous research, we showed that while a 12-month supervised exercise program improved the walking performance of PAD-IC patients, the improvement may not be due to changes in either lower limb temporal-spatial gait parameters, or angular kinematics. ${ }^{7}$ Therefore, physiological mechanisms may be responsible for the improved walking performance demonstrated in our research, ${ }^{7}$ and the research of others. ${ }^{16-18}$ Studies have demonstrated that supervised exercise programs can improve the peak aerobic capacity (ie, peak oxygen uptake, $\left[\mathrm{VO}_{2 \text { peak }}\right]$ ) of PAD-IC-affected individuals by an average of 1-3 $\mathrm{mL} \cdot \mathrm{kg}^{-1} \cdot \mathrm{min}^{-1}$ depending on the intensity and duration of the exercise sessions. ${ }^{10,12,19}$ Few studies have examined the possibility that exercise-induced improvements in pain-free and maximal walking time in this population may in fact be due to improved walking economy as indicated by reduced submaximal $\dot{\mathrm{VO}}_{2}$. An increase in walking submaximal economy efficiency may reflect an improvement in biomechanical and physiological components, thereby improving functional capacity. To our knowledge, there have been only a small number of studies to date which have examined submaximal walking economy in PAD patients. These studies demonstrated that walking economy, as measured by $\dot{\mathrm{V}} \mathrm{O}_{2}$ during the final minute of steady-state submaximal walking, improved following a 6-month exercise rehabilitation program, and strength increases in PAD patients correlated to decreases in $\mathrm{VO}_{2}$ measures. ${ }^{4,20}$ It should be noted that walking economy in these studies was assessed at a single time point: either the final or first minute of exercise prior to training, and then at the same time point following training, thereby ensuring the absolute workload was the same, and therefore comparable. However, the limitation of this might be the value of assessing economy during the first or final minute of a test, as the patients are likely to be relying heavily on anaerobic pathways and hyperventilating, which would significantly impair the ability to rely on indirect calorimetry for the determination of energy expenditure.

Further and more detailed analysis of submaximal walking is required to clarify the role of walking economy as a mechanism for walking performance improvement, following regular exercise. Alterations in submaximal walking economy may explain why patients increase their walking performance without an increase in peripheral blood flow, following supervised exercise programs. ${ }^{12,21}$

The aim of this study was to examine the effects of a 6-month supervised exercise program on both submaximal walking economy and walking performance in individuals with PAD-IC. It was hypothesized that the supervised exercise program would result in an improvement in both walking performance and submaximal walking economy during a graded walking treadmill test, compared to baseline and control PAD-IC participants.

\section{Materials and methods \\ Participants}

Patients referred to the Vascular Department at the Townsville Hospital (Queensland, Australia) with symptoms of IC were considered for inclusion in this study, as part of a larger study. ${ }^{6,7}$ Entry criteria included an appropriate history of IC, imaging confirmation of PAD on lower limb duplex or computed tomographic angiography (CTA), and ability and willingness to attend for regular supervised exercise. Exclusion criteria included selection for surgical or endovascular intervention $(n=30)$, patient preference $(n=20)$ and requirement for mobility aids, obvious gait abnormalities (eg, steppage, vaulting, circumduction and hip hiking), or medical conditions which influenced gait (eg, orthopedic conditions and neurological impairment). Clinical data, including atherosclerotic risk factors and medication history were collected during consultations with a vascular physician. Diabetes, hypertension, arthritis and ischemic heart disease were defined by history of diagnosis or previous treatment of these conditions. PAD-IC was confirmed by the absence of peripheral pulses, lower limb artery stenosis or occlusion on duplex or CTA, and anklebrachial pressure index $<0.9 .^{22}$

Participants were randomly allocated using a blinded protocol to either a control (CPAD-IC, $n=11)$ or treatment (TPAD-IC, $n=11$ ) group. Patients randomized to the TPAD-IC experimental condition undertook a 6-month supervised exercise program, while CPAD-IC patients continued with standard medical treatment as outlined in the Trans-Atlantic Inter-Society Consensus (TASC II) guidelines. ${ }^{23-25}$ All participants volunteered and gave written informed consent to participate in this study, with all procedures undertaken in accordance with the principles outlined in the Declaration of Helsinki. Approval for the study was 
obtained from both the local university and health district research ethics committees.

\section{Procedure}

Participants arrived at the laboratory in the early morning during a 12-hour fasting state, and underwent an assessment of body composition, resting ankle/brachial pressure index and a graded treadmill exercise test. The same procedures were completed prior to ( 0 -month) and following the intervention (6-month) period.

\section{Body composition}

Participant height was determined by a wall mounted stadiometer (model 220, Seca Scales, Hamburg, Germany). Body mass and composition ( $\%$ body fat) were determined via bioelectrical impedance scales (TANITA TBF 521, TANITA Corporation, Arlington Heights, Il).

\section{Ankle/brachial index}

Blood pressure measurements were taken by a qualified sonographer using a handheld bidirectional Doppler instrument (MD6, Hokanson, Bellevue, WA) with a 5-MHz transducer and standard blood pressure cuffs after the participant had rested in the supine position for 15 minutes. Ankle/ brachial index (ABI) was calculated as the highest systolic blood pressure in the posterior tibial artery or dorsalis pedis artery, divided by the highest systolic blood pressure in the left or right brachial artery. ${ }^{26}$

\section{Graded treadmill exercise test}

Participants then underwent a graded exercise test on a treadmill (Trackmaster TMX55, Full Vision, KS). The physiological responses assessed including $\dot{\mathrm{V}} \mathrm{O}_{2}$, respiratory exchange ratio (RER) and ventilation ( $\dot{\mathrm{VE}})$, were determined via indirect calorimetry using a metabolic cart (POWERLAB/8M Metabolic System, ADInstruments Pty Ltd, Castle Hill, Australia). Heart rate (HR) was recorded using a bioamp as previously described. ${ }^{7}$ All physiological responses were recorded continuously using Chart (v5.1, ADInstruments Pty Ltd) sampling at $1000 \mathrm{~Hz}$, and were later analyzed as 15-second averages. Walking economy was assessed by $\dot{\mathrm{VO}}_{2}$ at 15 -second periods during the graded treadmill test and compared against values predicted using the American College of Sports Medicine (ACSM) equations for a typical healthy population. ${ }^{27}$ Similar calculations have been utilized previously for walking economy in PAD patients. ${ }^{4}$

The graded treadmill walking protocol consisted of a constant speed of $3.2 \mathrm{~km} \cdot \mathrm{h}^{-1}\left(0.88 \mathrm{~m} \cdot \mathrm{s}^{-1}\right)$ at an incline of $0 \%$ for the first 2 minutes, which was then increased by $2 \%$ every 2 minutes. ${ }^{28}$ Participant perception of exercise exertion was determined every 60 seconds via Borg's Rating of Perceived Exertion (RPE) instrument, ${ }^{29}$ while participant perception of claudication pain was determined via a 5 -point scale, $(0=$ no pain, 1 = onset of pain, 2 = moderate pain, $3=$ intense pain, 4 = maximal pain) the Claudication Pain Scale (CPS). ${ }^{27}$ Walking performance was assessed as pain-free walking time (PFWT) and maximal walk time (MWT) determined via perceived maximal pain or volitional exhaustion.

\section{Supervised exercise program}

As previously described, ${ }^{7}$ the exercise program initially consisted of intermittent supervised treadmill walking 3 days per week for a total time of 25 minutes at $3.2 \mathrm{~km} \cdot \mathrm{hr}^{-1}$ $\left(0.88 \mathrm{~m} \cdot \mathrm{s}^{-1}\right)$. Participants were required to walk until the pain level was perceived as being 3 or 4 on the CPS. Exercise intensity (via treadmill grade and walking speed) and duration ( 25 minutes up to a maximum of 40 minutes) were progressively increased once the participant could walk continuously for 25 minutes at a level below 3 on the CPS pain scale. This exercise progression strategy was continued over the 6-month period of the study.

\section{Statistical analyses}

Statistical analyses were performed using the SPSS software program (v16.0, SPSS Inc, Chicago, Il). Descriptive statistics were expressed as mean ( $\pm \mathrm{SD})$. Box-plot analyses were performed to identify extreme and outlier data. Medication and comorbidities data were analyzed using the nonparametric Friedman test, and post hoc comparison using Nemenyi's test. Due to the restricted sample size, multiple KruskalWallis tests were performed for CPAD-IC versus TPAD-IC at 0 months and CPAD-IC versus TPAD-IC at 6 months. An alpha level of 0.05 was adopted for this study. ${ }^{30}$ Due to the limited walking ability of some participants (perceived maximal pain or volitional exhaustion within 3 minutes), walking economy was only assessed for the first 3 minutes of the graded treadmill test, in order to provide maximal comparison between groups. The TPAD-IC group attended $80 \%$ of the training sessions during the 6-month period of the study.

\section{Results \\ Participants}

The participant groups were similar in age, height, mass and \% body fat at baseline $(P>0.05)$. For personal reasons, six participants $(\mathrm{n}=5$ CPAD-IC and $\mathrm{n}=1$ TPAD-IC) 
withdrew over the course of the research study. Baseline data for the two groups were similar after excluding the patients that dropped out (Table 1). Both groups had bilateral PAD, as indicated by ABI, with similar severity between groups. The groups were similar with respect to risk factors, comorbidities and medications; however, the CPAD-IC group consisted of a higher proportion of patients who had been diagnosed with hypertension $(P<0.05)$, compared to the TPAD-IC group (Table 1).

\section{Treadmill testing}

The groups had similar PFWT and MWT at baseline. Following the 6-month supervised exercise program, TPADIC participants demonstrated significantly greater PFWT and MWT compared to the CPAD-IC group (Table 2). All peak physiological responses (HR, $\dot{\mathrm{VO}}_{2}, \dot{\mathrm{VE}}$ and RER) were similar between groups at baseline, and following the 6-month intervention (Figures 1 and 2).

Walking economy was similar at baseline in both groups, and was greater than that for a healthy population based on the ACSM equations (Figure 1A). Following the 6-month supervised exercise program, the TPAD-IC demonstrated significantly-reduced $\dot{\mathrm{VO}}_{2}$ during the graded treadmill test at the 60,75 , and 180 second intervals, and had values closer to those for a healthy population based on the ACSM equations (Figure 1B). During the graded treadmill walk, TPAD-IC displayed significantly-reduced RER values from 90 seconds until 180 seconds, compared to CPAD-IC postintervention
(Figure 2D). A correlation analysis found a low-to-moderate result between walking economy and MWT for both 0 and 6 months.

\section{Discussion}

The purpose of this study was to investigate the effects of a 6-month supervised exercise program on submaximal walking economy and walking performance of individuals with PAD-IC. The results of this study impact upon those of others, ${ }^{4,31}$ by demonstrating some significant improvements in submaximal walking economy during the testing protocol following regular exercise. The submaximal walking economy values from the current study were similar to those reported by Gardner et al, ${ }^{4}$ with the TPAD-IC group improving their PFWT and MWT by $245 \%$ and $128 \%$ respectively, said values being greater than those previously exhibited by PAD patients. ${ }^{4}$

The current results indicate that enhanced submaximal walking economy contributes to improved walking performance for PAD-IC patients following regular exercise. Furthermore, the improved walking economy of TPAD-IC patients appears to approach values predicted by the ACSM equations for healthy adults. This trend suggests that regular exercise enhances submaximal walking economy towards healthy values which may in turn contribute to greater independence for PAD-IC patients. ${ }^{10}$

While greater submaximal walking economy was demonstrated by TPAD-IC, the mechanism(s) for such improvement

Table I Descriptive characteristics of participants

\begin{tabular}{|c|c|c|c|c|}
\hline \multirow[t]{2}{*}{ Variable } & \multicolumn{2}{|l|}{$\begin{array}{l}\text { CPAD-IC } \\
(n=6)\end{array}$} & \multicolumn{2}{|l|}{$\begin{array}{l}\text { TPAD-IC } \\
(\mathrm{n}=10)\end{array}$} \\
\hline & 0 month & 6 months & 0 month & 6 months \\
\hline Age $(y)$ & $67.1( \pm 6.8)$ & $68.1( \pm 6.8)$ & $71.3( \pm 8.5)$ & $72.3( \pm 8.5)$ \\
\hline Height $(\mathrm{cm})$ & $167.7( \pm 3.0)$ & $168.0( \pm 3.2)$ & $165.7( \pm 2.4)$ & $165.7( \pm 2.5)$ \\
\hline Mass (kg) & $72.4( \pm 6.0)$ & $72.8( \pm 6.0)$ & $80.7( \pm 4.6)$ & $79.4( \pm 4.6)$ \\
\hline Body fat (\%) & $29.2( \pm 3.6)$ & $30.5( \pm 2.6)$ & $33.1( \pm 2.8)$ & $34.5( \pm 2.0)$ \\
\hline BMI $\left(\mathrm{kg} \cdot \mathrm{m}^{-2}\right)$ & $25.7( \pm 4.9)$ & $25.8( \pm 5.4)$ & $29.2( \pm 4.1)$ & $28.8( \pm 3.9)$ \\
\hline$A B I$ left leg & $0.53( \pm 0.08)$ & $0.53( \pm 0.08)$ & $0.72( \pm 0.06)$ & $0.70( \pm 0.06)$ \\
\hline$A B \mid$ right leg & $0.66( \pm 0.11)$ & $0.69( \pm 0.11)$ & $0.71( \pm 0.09)$ & $0.74( \pm 0.09)$ \\
\hline Gender ( $\%$ male $)$ & $50 \%$ & & $50 \%$ & \\
\hline Current smoker (\%) & $30 \%$ & & $10 \%$ & \\
\hline Former smoker (\%) & $75 \%$ & & $77 \%$ & \\
\hline Type II diabetes (\%) & $17 \%$ & & $10 \%$ & \\
\hline Hypertension (\%) & $50 \%$ & & $10 \% *$ & \\
\hline Ischemic heart disease (\%) & $33 \%$ & & $20 \%$ & \\
\hline Arthritis (\%) & $0 \%$ & & $10 \%$ & \\
\hline Beta-blocker prescription (\%) & $33 \%$ & & $10 \%$ & \\
\hline
\end{tabular}

Notes: Values are mean $( \pm S D)$ or $\% * P<0.01$ versus CPAD-IC.

Abbreviations: ABI, Ankle/brachial index; BMI, Body Mass Index; CPAD-IC, control peripheral arterial disease-intermittent claudication patients; TPAD-IC, treatment peripheral arterial disease-intermittent claudication patients. 
Table 2 Pain free walking time and maximal walking time prior to and following 6 month supervised exercise training

\begin{tabular}{|c|c|c|c|c|}
\hline & \multicolumn{2}{|l|}{0 month } & \multicolumn{2}{|l|}{6 months } \\
\hline & $\begin{array}{l}\text { CPAD-IC } \\
(\mathrm{n}=10)\end{array}$ & $\begin{array}{l}\text { TPAD-IC } \\
(n=6)\end{array}$ & $\begin{array}{l}\text { CPAD-IC } \\
(\mathrm{n}=10)\end{array}$ & $\begin{array}{l}\text { TPAD-IC } \\
(\mathrm{n}=6)\end{array}$ \\
\hline \multirow[t]{2}{*}{ PFWT (s) } & II5.7 & 134.8 & 139.8 & 465.5 \\
\hline & $( \pm 97.9)$ & $( \pm 54.1)$ & $( \pm 79.7)$ & $( \pm 325.1)^{*}$ \\
\hline \multirow[t]{2}{*}{ MWT (s) } & 288.2 & 335.5 & 360.7 & 766.9 \\
\hline & $( \pm 100.8)$ & $( \pm \mid 40.2)$ & $( \pm|3| .9)$ & $( \pm 3 \mid 7.9)^{*}$ \\
\hline
\end{tabular}

Notes: Values are mean $( \pm S D)$. $* P<0.05$ versus 6-month CPAD-IC.

Abbreviations: CPAD-IC, control peripheral arterial disease-intermittent claudication patients; MWT, maximal walking time; PFWT, pain free walking time; TPAD-IC, treatment peripheral arterial disease-intermittent claudication patients.

remains unknown. Prior studies have reported an increase in peripheral limb blood for PAD-IC patients at rest following an exercise program; $;, 15$ however, increased blood flow during exercise remains controversial due to sound methodology to measure blood flow during exercise. ${ }^{12,19}$ Increased limb blood flow may result in increased oxygen supply/perfusion, reduced submaximal $\dot{\mathrm{VO}}_{2}$, improved walking economy and reduced claudication pain. The current study demonstrated that submaximal $\dot{\mathrm{VO}_{2}}$ was reduced after an exercise training program, and may provide an indirect indicator of improved peripheral limb blood flow during exercise for TPAD-IC patients. Training-induced increases in oxygen saturation of the calf muscle during treadmill walking provides further support for improved lower-limb oxygen delivery for PAD patients. ${ }^{32}$

While improved blood flow has been proposed, the consistent lack of training-induced increases of resting and postexercise blood flow, ${ }^{15}$ and minimal changes in angiogenic factors, ${ }^{33}$ imply that other mechanisms may contribute to the greater walking performance for PAD patients, post-training. For example, Figoni et $\mathrm{al}^{34}$ reported lower oxygen saturation levels (greater calf deoxygenation) during exercise for PAD participants following regular exercise. The lower saturation values represented increased tissue perfusion and enhanced oxygen extraction as a result of regular exercise training. ${ }^{34}$

A

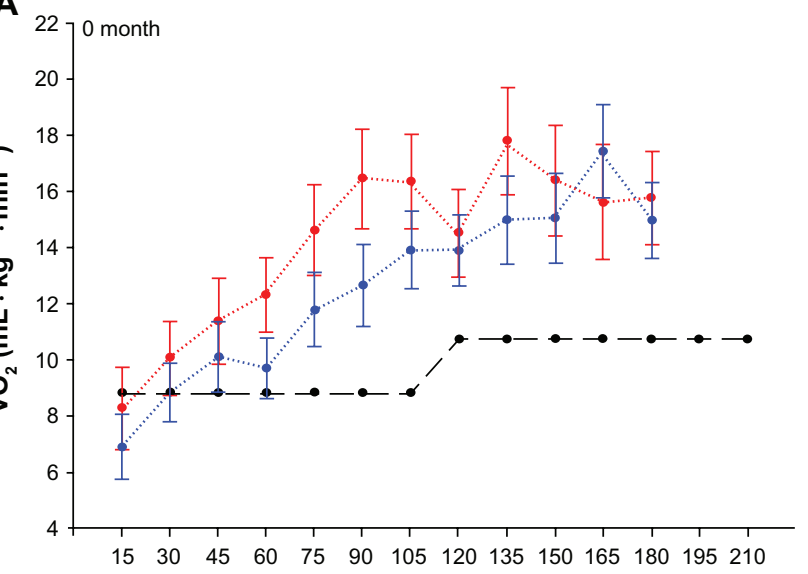

B

Time (seconds)

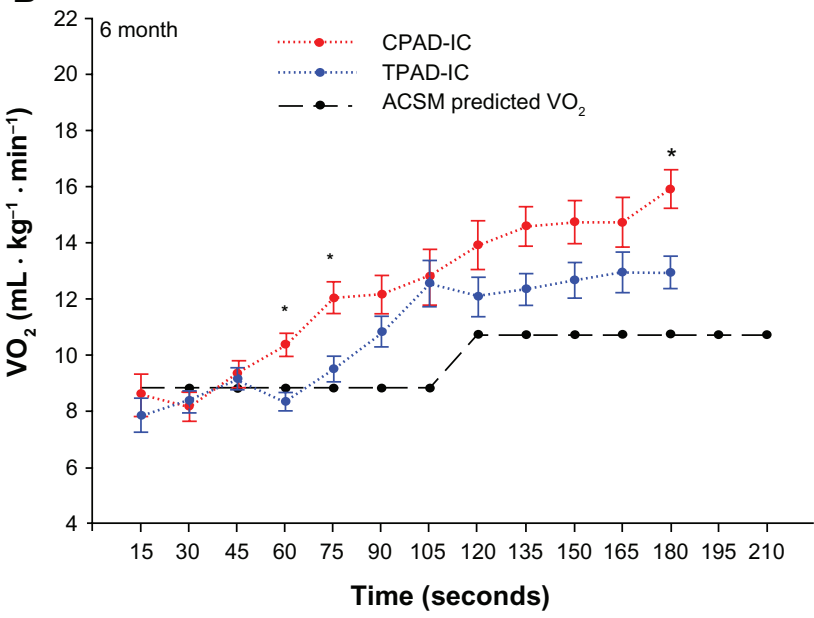

Figure I Walking economy during graded treadmill testing at 0 - and 6-months for control peripheral arterial disease-intermittent claudication patients (CPAD-IC) and treatment for peripheral arterial disease-intermittent claudication patients (TPAD-IC).

Note: $* P<0.05$ versus TPAD-IC 


\section{0 month}

A

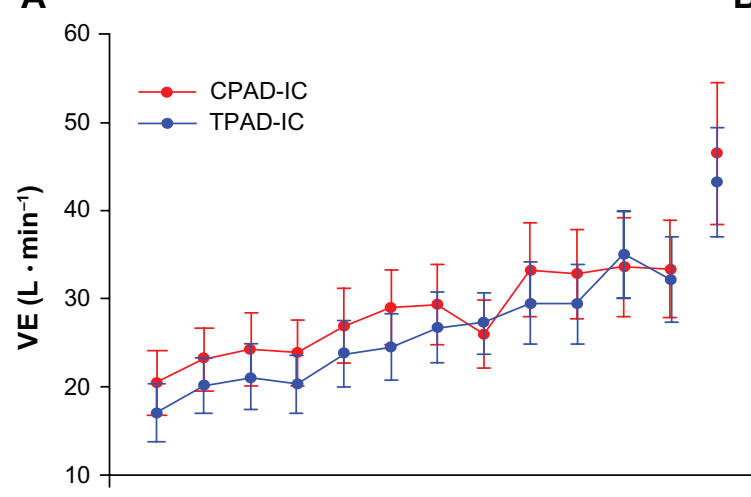

D

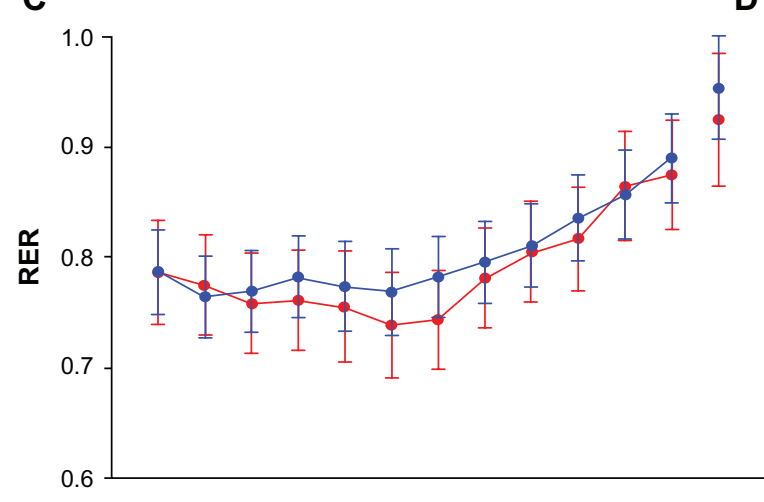

E

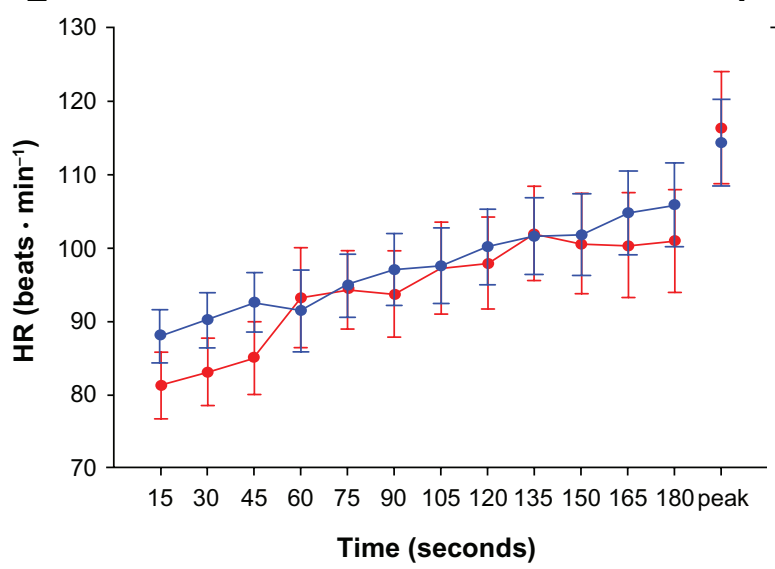

B

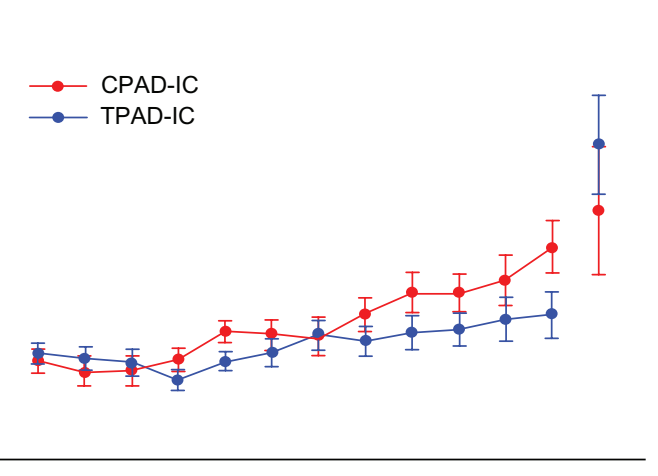

6 month

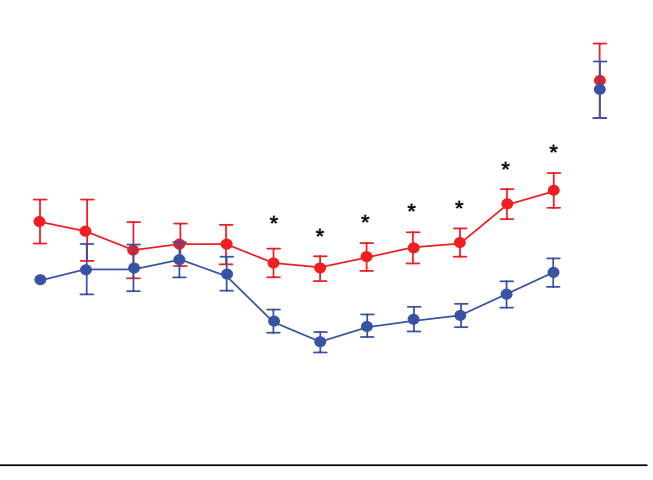

F

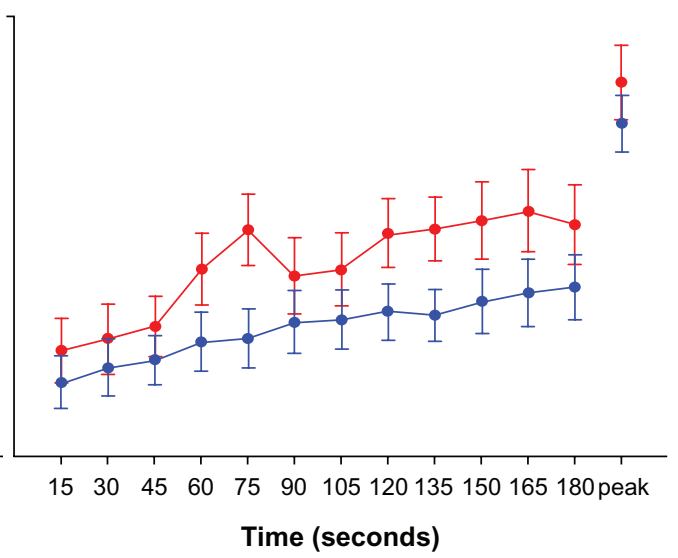

Figure 2 Submaximal and peak physiological characteristics during graded treadmill testing at 0 - and 6-months for control peripheral arterial disease-intermittent claudication patients (CPAD-IC) and treatment for peripheral arterial disease-intermittent claudication patients (TPAD-IC).

Note: $* P<0.05$ versus TPAD-IC.

Similar results of greater oxygen extraction during exercise have been seen in animals, with signs of IC following high intensity training. ${ }^{35}$ These authors reported greater mitochondrial content post-training as a contributing factor for the training-induced improved performance. ${ }^{35}$ Others have proposed similar improvements in localized muscle metabolism for the training-induced improvements in muscular activity. ${ }^{36,37}$ Most notably, carnitine, an important cofactor involved in lipid metabolism, has been augmented following training in PAD patients. ${ }^{36,37}$

Subsequently, regular training may result in greater carnitine and lipid metabolism for PAD-IC patients. During the submaximal walking test, TPAD-IC patients exhibited significantly-reduced RER values, which are indicative of an increased lipid metabolism. Enhanced lipid use reflects an important training-induced adaptation following regular 
exercise, ${ }^{38,39}$ and, more importantly, may provide a key factor for the treatment of PAD. Given the significant relationship between obesity and PAD severity, and the risk of outcome events, ${ }^{40}$ the current results of greater lipid metabolism during submaximal walking provide further evidence of the benefits of regular exercise for the treatment of PAD-IC patients.

At present, the exact mechanisms for greater walking performance and lower submaximal walking economy in PAD-IC patients following regular exercise training are yet to be clarified. Examination of such variable factors as oxygen and blood flow kinetics during exercise, muscle metabolism, and mitochondrial content, will further clarify the role of these factors for improved walking performance and economy in PAD-IC patients.

\section{Limitations}

The main limitation of the current study was the small sample size, particularly the number of patients followed up at 6 months. While studies with greater patient numbers may provide further evidence for the impact of PAD on submaximal walking economy, comparable results between the current and prior study (maximal walking economy only $)^{3}$ provide support for the significant influence of regular exercise on submaximal walking economy for PAD patients.

Additionally, although the CPAD-IC group was not followed up with respect to other lifestyle factors during the 6 months, the intent of this research study was to examine the differences between a supervised exercises group and a standard medical treatment group. Research may wish to place more control on participants' medical treatment and general lifestyle in the future.

\section{Conclusion}

In conclusion, the results of this study demonstrated that a 6-month supervised exercise program resulted in improved walking economy and greater fat metabolism during submaximal walking, and maximal walking performance for PAD-IC patients without significant alterations in peak physiological characteristics. The improved maximal walking performance for patients following regular exercise may be associated with improvements in submaximal walking economy, with further research to clarify the respective contributions of peripheral blood flow, muscle fiber and mitochondrial density to walking economy in PAD patients.

\section{Acknowledgments}

This work is from a National Health and Medical Research Council-funded Clinical Centre of Research Excellence to improve the management of peripheral artery disease. JG is supported by a Practitioner Fellowship from the NHMRC, and a Senior Clinical Research Fellowship from the Office of Health and Medical Research.

\section{Disclosure}

The authors report no conflicts of interest in this work.

\section{References}

1. Bendermacher BL, Willigendael EM, Teijink JA, Prins MH. Medical management of peripheral arterial disease. J Thromb Haemost. 2005; 3(8):1628-1637.

2. Beebe HG. Intermittent claudication: effective medical management of a common circulatory problem. Am J Cardiol. 2001;87(12A): 14D-18D.

3. Bauer TA, Brass EP, Nehler M, Barstow TJ, Hiatt WR. Pulmonary $\mathrm{VO} 2$ dynamics during treadmill and arm exercise in peripheral arterial disease. J Appl Physiol. 2004;97(2):627-634.

4. Gardner AW, Katzel LI, Sorkin JD, Goldberg AP. Effects of longterm exercise rehabilitation on claudication distances in patients with peripheral arterial disease: a randomized controlled trial. J Cardiopulm Rehabil. 2002;22(3):192-198.

5. Leicht AS, Crowther RG, Muller R, Golledge J. The effects of including quality of life responses in models to predict walking performance of patients with intermittent claudication. Eur J Vasc Endovasc Surg. 2011;41(4):511-517.

6. Crowther RG, Spinks WL, Leicht AS, Quigley F, Golledge J. Relationship between temporal-spatial gait parameters, gait kinematics, walking performance, exercise capacity, and physical activity level in peripheral arterial disease. J Vasc Surg. 2007;45(6):1172-1178.

7. Crowther RG, Spinks WL, Leicht AS, Sangla K, Quigley F, Golledge J. Effects of a long-term exercise program on lower limb mobility, physiological responses, walking performance, and physical activity levels in patients with peripheral arterial disease. J Vasc Surg. 2008;47(2): 303-309.

8. Gardner AW, Poehlman ET. Exercise rehabilitation programs for the treatment of claudication pain. A meta-analysis. JAMA. 1995;274(12): 975-980.

9. Gardner AW, Katzel LI, Sorkin JD, et al. Exercise rehabilitation improves functional outcomes and peripheral circulation in patients with intermittent claudication: a randomized controlled trial. J Am Geriatr Soc. 2001;49(6):755-762.

10. Gardner AW, Katzel LI, Sorkin JD, et al. Improved functional outcomes following exercise rehabilitation in patients with intermittent claudication. J Gerontol A Biol Sci Med Sci. 2000;55(10):M570-M577.

11. Lumsden AB, Rice TW. Medical management of peripheral arterial disease: a therapeutic algorithm. J Endovasc Ther. 2006;13 Suppl 2: II19-II29.

12. Slørdahl SA, Wang E, Hoff J, Kemi OJ, Amundsen BH, Helgerud J. Effective training for patients with intermittent claudication. Scand Cardiovasc J. 2005;39(4):244-249.

13. Ernst EE, Matrai A. Intermittent claudication, exercise, and blood rheology. Circulation. 1987;76(5):1110-1114.

14. Jaquinandi V, Abraham P, Picquet J, Paisant-Thouveny F, Leftheriotis G, Saumet JL. Estimation of the functional role of arterial pathways to the buttock circulation during treadmill walking in patients with claudication. J Appl Physiol. 2007;102(3):1105-1112.

15. Parmenter BJ, Raymond J, Fiatarone Singh MA. The effect of exercise on haemodynamics in intermittent claudication: a systematic review of randomized controlled trials. Sports Med. 2010;40(5): 433-447.

16. Carlon R, Morlino T, Maiolino P. Beneficial effects of exercise beyond the pain threshold in intermittent claudication. Ital Heart J. 2003;4(2):113-120. 
17. Leng GC, Fowler B, Ernst E. Exercise for intermittent claudication. Cochrane Database Syst Rev. 2000(2):CD000990.

18. Menard JR, Smith HE, Riebe D, Braun CM, Blissmer B, Patterson RB. Long-term results of peripheral arterial disease rehabilitation. $J$ Vasc Surg. 2004;39(6):1186-1192.

19. Womack CJ, Sieminski DJ, Katzel LI, Yataco A, Gardner AW. Improved walking economy in patients with peripheral arterial occlusive disease. Med Sci Sports Exerc. 1997;29(10):1286-1290.

20. Ritti-Dias RM, Wolosker N, de Moraes Forjaz CL, et al. Strength training increases walking tolerance in intermittent claudication patients: randomized trial. J Vasc Surg. 2010;51(1):89-95.

21. Tan KH, Cotterrell D, Sykes K, Sissons GR, de Cossart L, Edwards PR. Exercise training for claudicants: changes in blood flow, cardiorespiratory status, metabolic functions, blood rheology and lipid profile. Eur J Vasc Endovasc Surg. 2000;20(1):72-78.

22. Leng GC, Fowkes FG. The Edinburgh claudicatiosn questionnaire: an improved version of the WHO/Rose questionnaire for use in epidemiological surveys. J Clin Epidemiol. 1992;45(10):1101-1109.

23. Norgren L, Hiatt WR, Dormandy JA, Nehler MR, Harris KA, Fowkes FG. Inter-society consensus for the management of peripheral arterial disease (TASC II). J Vasc Surg. 2007;45 Suppl:S5-S67.

24. Norgren L, Hiatt WR, Dormandy JA, et al. Inter-society consensus for the management of peripheral arterial disease (TASC II). Eur J Vasc Endovasc Surg. 2007;33 Suppl 1:S1-S75.

25. Norgren L, Hiatt WR, Dormandy JA, et al. Inter-society consensus for the management of peripheral arterial disease. Int Angiol. 2007;26(2): 81-157.

26. Caruana MF, Bradbury AW, Adam DJ. The validity, reliability, reproducibility and extended utility of ankle to brachial pressure index in current vascular surgical practice. European Journal of Vascular and Endovascular Surgery. 2005;29:443-451.

27. American College of Sports Medicine. Guidelines for Exercise Testing and Prescription. 7th ed. Philadelphia: Lea and Febiger; 2006.

28. Gardner AW, Skinner JS, Cantwell BW, Smith LK. Progressive vs single-stage treadmill tests for evaluation of claudication. Medicine and Science in Sports and Exercise. 1991;23(4):402-408.
29. Borg G. Perceived exertion as an indicator of somatic stress. Scandinavian Journal of Rehabilitation Medicine. 1970;2:92-98.

30. Vincent WJ. Statistics in Kinesiology. 3rd ed. Champaign, II: Human Kinetics; 2005.

31. Ritti-Dias RM, Wolosker N, de Moraes Forjaz CL, et al. Strength training increases walking tolerance in intermittent claudication patients: randomized trial. J Vasc Surg. 2010;51(1):89-95.

32. Tew G, Nawaz S, Zwierska I, Saxton JM. Limb-specific and cross-transfer effects of arm-crank exercise training in patients with symptomatic peripheral arterial disease. Clin Sci (London). 2009;117(12): 405-413.

33. Wood RE, Sanderson BE, Askew CD, Walker PJ, Green S, Stewart IB. Effect of training on the response of plasma vascular endothelial growth factor to exercise in patients with peripheral arterial disease. Clin Sci (London). 2006;111(6):401-409.

34. Figoni SF, Kunkel CF, Scremin AM, et al. Effects of exercise training on calf tissue oxygenation in men with intermittent claudication. PMR. 2009;1(10):932-940.

35. Erney TP, Mathien GM, Terjung RL. Muscle adaptations in trained rats with peripheral arterial insufficiency. Am J Physiol. 1991; 260(2 Pt 2):H445-H452.

36. Hiatt WR, Regensteiner JG, Hargarten ME, Wolfel EE, Brass EP. Benefit of exercise conditioning for patients with peripheral arterial disease. Circulation. 1990;81(2):602-609.

37. Hiatt WR, Regensteiner JG, Wolfel EE, Carry MR, Brass EP. Effect of exercise training on skeletal muscle histology and metabolism in peripheral arterial disease. J Appl Physiol. 1996;81(2):780-788.

38. Izquierdo-Porrera AM, Gardner AW, Powell CC, Katzel LI. Effects of exercise rehabilitation on cardiovascular risk factors in older patients with peripheral arterial occlusive disease. Journal of Vascular Surgery. 2000;31(4):670-677.

39. Solomon TP, Sistrun SN, Krishnan RK, et al. Exercise and diet enhance fat oxidation and reduce insulin resistance in older obese adults. $J \mathrm{Appl}$ Physiol. 2008;104(5):1313-1319.

40. Golledge J, Leicht A, Crowther RG, Clancy P, Spinks WL, Quigley F. Association of obesity and metabolic syndrome with the severity and outcome of intermittent claudication. J Vasc Surg. 2007;45(1):40-46.
Vascular Health and Risk Management

\section{Publish your work in this journal}

Vascular Health and Risk Management is an international, peerreviewed journal of therapeutics and risk management, focusing on concise rapid reporting of clinical studies on the processes involved in the maintenance of vascular health; the monitoring, prevention and treatment of vascular disease and its sequelae; and the involvement of

\section{Dovepress}

metabolic disorders, particularly diabetes. This journal is indexed on PubMed Central and MedLine. The manuscript management system is completely online and includes a very quick and fair peer-review system, which is all easy to use. Visit http://www.dovepress.com/ testimonials.php to read real quotes from published authors. 